\title{
From personalized medicine to personalized justice: the promises of translational pharmacogenomics in the justice system
}

\author{
"Personalized justice complements personalized medicine and the overlapping \\ practice of translational medicine, which holds that individual differences are \\ caused primarily by genetic and environmental factors."
}

Enabled by pharmacogenomics (PGx), molecular imaging and other molecular biomarkers, personalized medicine (PM) promises to optimize therapy while minimizing side effects. It may also dramatically impact the justice system in ways we are only beginning to understand.

Personalized medicine has already entered the curricula of well-regarded medical schools such as that of Johns Hopkins University (MD, USA) [1], but law schools offer no analog. Although clinical acceptance of PM has proved slow even with US FDA support $[2,101]$, PM's legal ramifications are evident. Recently, for example, the FDA relabeled some drugs with companion PGx [2], such as warfarin withCYP2C9 and vitamin K epoxide reductase complex 1 to reduce bleeding [3,4,101]. If PGx retrospectively reveals that the warfarin patient was at high risk and testing was not initially performed, litigation may follow. Indeed, some lawyers advertise on the internet for cases involving warfarin-related errors [102]. Consequently, PGx may become part of defensive medicine.

Personalized justice (PJ) complements PM and the overlapping practice of translational medicine [5-8], which holds that individual differences are caused primarily by genetic and environmental factors. The acronym 'TSPB' captures its elements in relation to adverse drug reactions (ADRs): toxicity, sensitivity, impaired performance (e.g., driving under the influence of drugs) and behavioral changes. Future legal applications may include molecular imaging and analyses - genomic, proteomic, metabolomics and epigenetics/imprintomics. By comparison, molecular DNA fingerprinting for identity testing is well accepted [9]. Conceptually, Figure 1 proposes a social-balance relationship for PM and PJ [8].

In assessing PJ, consider two index scenarios:

- Drug toxicity: a 9-year old boy, diagnosed with attention-deficit hyperactivity disorder, obsessive-compulsive disorder, and Tourette's syndrome, was treated with methylphenidate, clonidine and fluoxetine [10]. Over a 10-month period, he developed gastrointestinal toxicity, incoordination and disorientation, and seizures. He died from a cardiac arrest. Postmortem toxicology showed high fluoxetine and norfluoxetine concentrations, and PGx revealed a poor CYP2D6 metabolizer genotype, resulting in fluoxetine accumulation and toxicity. Subsequently, the boy's parent were absolved from involvement in fluoxetine intoxication. Another example is genotyping uridine 5'-diphosphate-glucuronyltransferase $1 \mathrm{~A} 1$ for patients medicated with irinotecan to avoid hematopoietic toxicity [11];

- Drug sensitivity: in addition to warfarin, one should genotype $H L A-B^{*} 5701$ [12] and $H L A-B^{*} 1502$ [13] for patients medicated with abacavir [12] and some antiepileptics [13], respectively, to avoid Stevens-Johnson syndrome. Lawyers use internet advertising to reach persons who may be affected [103].

In establishing PJ, a firm foundation should be based on sound legal principles as well as reliable and valid evidence-based studies, not on 'junk' science and unsubstantiated case reports. This lesson resonates in the deficiencies that beset various forensic sciences recently reported by the National Academy of Science [14,104]. The American Academy of Forensic Sciences supports the National Academy of Science's 13 recommendations and the following principles: the need for strong scientific foundations; laboratory accreditation; certification of technicians; the standardization of terminology; ethical protocols; governmental oversight; and the education of legal professionals, including judges, in forensic scientific methods and principles $[15,16,105]$. It is imperative that PJ heeds these recommendations, including the study of the relationship

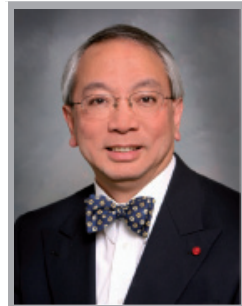

Steven HY Wong ${ }^{\dagger}$,

Christopher Happy,

Dan Blinka, Susan Gock,

Jeffrey M Jentzen,

Hon. Joseph Donald,

Howard Coleman,

Saeed A Jortani,

Yolande Lucire, Cynthia

L Morris-Kukoski,

Manuela G Neuman,

Paul J Orsulak,

Tara Sander,

Michael A Wagner,

Jennifer R Wynn,

Alan HB Wu \&

Kiang-Teck J Yeo

'Author for correspondence:
Medical College of Wisconsin

Milwaukee, WI 53226-0509, USA

Tel.: +1 4148056971

Fax: +14148056980

shwong@mow.edu

For a full list of affiliations, please see the back of this article.

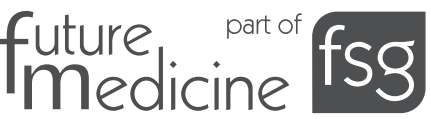




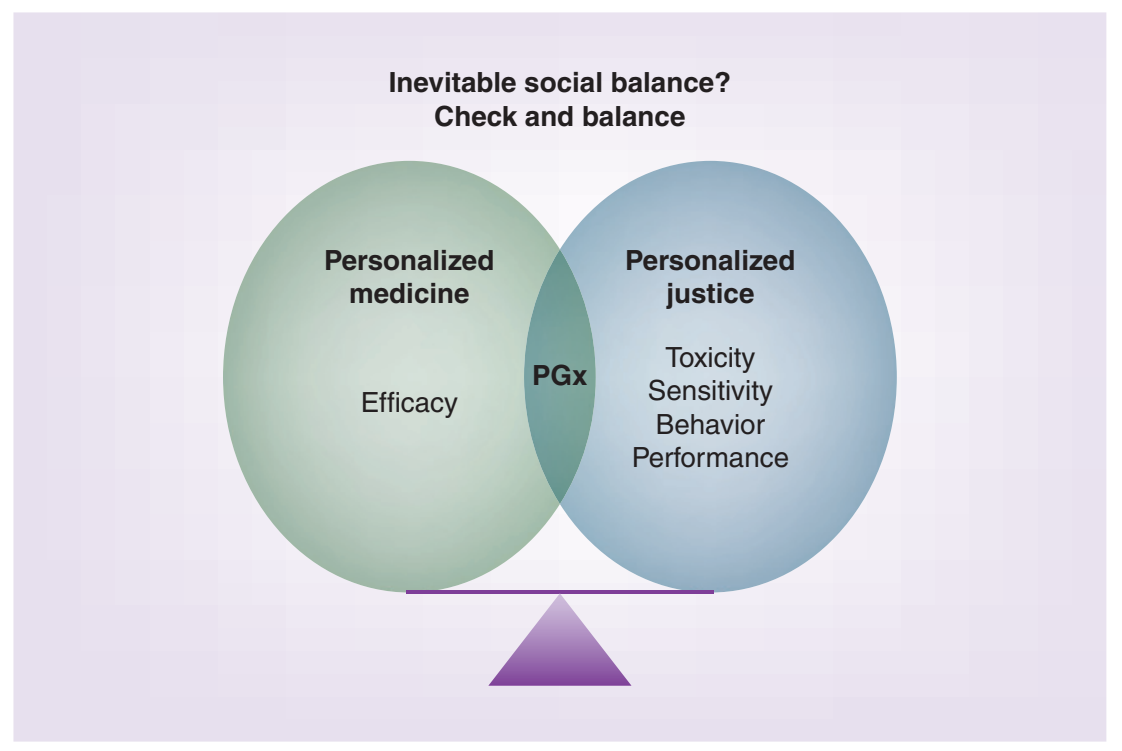

Figure 1. Complementary relationship of personalized medicine and personalized justice.

Reproduced and modified with permission from [8]. has become the 'gold standard' for forensic sciences. Thus, the DNA channel may provide a helpful port of entry for PJ.

\section{"It will be important then to educate judges, lawyers and legal academics about the explanatory power of personalized justice and personalized medicine."}

The prime questions though will relate to the role PJ will play in the legal system. DNA evidence thus far is narrowly confined to trace evidence: was this biological evidence left by the defendant or someone else? A thornier problem occurs when we attempt to apply biological evidence to moral culpability, which pertains to an accused's personal blameworthiness. The Supreme Court recognized in Penry $v$. Lynaugh that punishment for a criminal offense should be directly related to the defendant's personal culpability [21]. The concept of personal culpability acknowledges that human choices are shaped by many factors: genetic, neurological, intellectual, educational, social and environmental. It follows then that an individual's blameworthiness for criminal conduct may vary depending on the factors that shaped his moral development or compromised his choices. myth, proposing a legal framework, updating the reader on rapidly developing technological advances, and illustrating scenarios and published cases.

\section{Legal framework}

While personalized medicine is rapidly taking root among the medical sciences, one may reasonably expect a slower, more begrudging acceptance by the legal profession. Law is innately conservative and reluctant to accommodate dramatic change. 'Cutting-edge' developments of all sorts often take decades to gain a foothold [17]. It will be important then to educate judges, lawyers and legal academics about the explanatory power of PJ and PM. The law's incredibly rich experience with DNA developments may, however, facilitate this task [18].

One set of barriers consists of evidence rules, particularly those involving expert opinion testimony. The vaunted 'Daubert standard', pioneered by the federal courts and adopted by many states, demands that judges serve as gatekeepers who will ensure that only 'reliable' science is admitted [19]. Although courts have been distressingly inconsistent in how they scrutinize most sciences [20], DNA evidence

\section{“...should courts consider identifiable biological conditions that predispose a person to criminal behavior in weighing moral culpability? Legal precedent suggests that it should."}

Thus, from a PJ perspective, the question becomes something like this: should courts consider identifiable biological conditions that predispose a person to criminal behavior in weighing moral culpability? Legal precedent suggests that it should. Consider Roper $v$. Simmons, where the Supreme Court held that persons under the age of 18 years could not be subjected to the death penalty because their brains were not yet fully developed [22]. MRIs and neuroimaging showed that neuronal changes in the brain continued to develop into the early twenties. Since the brain affects behavior, the justices ruled that punishing a person for behavior caused by an underdeveloped brain (of which the defendant had no choice) violated the prohibition against cruel and unusual punishment. Similar logic was applied in Atkins v. Virginia, which prohibited subjecting the mentally retarded defendants to 
the death penalty [23]. Roper and Atkins illustrate the principle that criminal defendants with brain-based deficits are not as morally culpable as those without. As such, they deserve a lesser penalty. This is a legal springboard for PJ.

\section{Forensic pathology perspectives}

For several medical examiner/coroner offices in the USA and Europe, PGx has served as an adjunct for drug death certification - an emerging practice of molecular autopsy $[7,8]$. Previous studies showed a higher prevalence of CYP2D 6 genetic variations, corresponding to intermediate and slow metabolizers with decreased or without enzymatic activity, in the decedents intoxicated with methadone, oxycodone and antidepressants $[7,8,24,25]$. Thus, PGx might aid in the interpretation of the effect of impaired drug metabolism due to genetic variations. If potentially lethal medications are identified at the scene of a crime with correspondingly toxic drug concentrations of the decedent, and subsequent PGx testing confirms an 'extensive' (normal) metabolizer, death is certified as a suicide. If the deceased's genotype is a variant - resulting in decreased drug metabolism - death is certified as accident. Recent indications of PJ for forensic pathology include a PGx section in the forensic toxicology texts for medical examiners by Molina [26] and Karch [27]. Future molecular diagnostic biomarkers of interest might include epigenetics/imprintomics and gene expression in understanding suicide $[28,29]$, metabolomics and proteomics [8].

"...criminal defendants with brain-based deficits are not as morally culpable as those without. As such, they deserve a lesser penalty. This is a legal springboard for personalized justice."

\section{Molecular diagnostics}

The detection of individual genetic variants is at the heart of PM and PJ. SNPs, the most common type of genetic variation, might affect drug metabolism [30]. Several SNP genotyping technologies facilitate rapid PGx testing in clinical laboratories. The three main steps, DNA extraction, amplification and detection, may be performed by automated platforms. Biotechnology companies offering PGx testing platforms, some with FDA approval, include: Luminex $\mathrm{xTag}^{\circledR}$ (Luminex Corporation, TK, USA), Roche AmpliChip ${ }^{\circledR}$ (Roche, Basel, Switzerland), Affymetrix DMET $^{\circledR}$ chip (Affymetrix, CA, USA), Autogenomics INFINITITM Analyzer (Autogenomics, CA, USA), Osmetech eSensors ${ }^{\circledR}$ (WA, USA), ParagonDx (NC, USA), and ABI PRISM ${ }^{\circledR}$ SNaPshot ${ }^{\mathrm{TM}}$ (Applied Biosystems, CA, USA) and TaqMan ${ }^{\circledR}$ assays (Applied Biosystems). Thus, the laboratory can rapidly develop, validate and perform PGx testing in-house within months, further enhanced by readily available quality-control products and survey programs. The limitations include existing evidence to demonstrate significant and medically relevant correlations for many disease-causing genes and variants, limited detection of genetic variants within the context of each testing platform, clinical interpretation of genotype results including environmental factors, and transplanted organs interfering with testing.

“...in the USA and Europe, pharmacogenomics has served as an adjunct for drug death certification - an emerging practice of molecular autopsy."

\section{Drug hypersensitivity in vitro diagnostics}

In vitro lymphocyte toxicity assays (LTAs) compares the peripheral blood lymphocytes of patients with a history of an ADR with control individuals who take the same drug in the same dose and do not present any ADR [31]. LTA is based upon the dysfunction of mitochondria in people hypersensitive to certain drugs, such as sulfonamides, NSAIDs, protease inhibitors and antiepileptics. This test can also detect possible drug-drug interactions. Dysfunction of mitochondria has severe cellular consequences and is linked to a lack of detoxification of drugs in humans. Several surveillance strategies have evolved that limit mitochondrial damage and ensure cellular integrity. Intra-organellar proteases conduct protein quality control and exert regulatory functions, allowing the mitochondria to protect against apoptosis. LTA can be used in PJ when several drugs are implicated in an ADR in order to enable a distinction between the drug that produced the reaction and the other drugs, which were taken in the same period of time but did not contribute to the ADR.

\section{Illustrative cases \& scenarios Alcohol}

Alcoholism, with up to $30-40 \%$ inheritability, is a complex and controversial disease 
with both environmental and genetic components. Genetic variations influence alcohol's pharmacokinetics/metabolism and pharmacodynamics. Alcohol dehydrogenase and acetaldehyde dehydrogenase are two main polymorphic enzymes involved in alcohol metabolism, with a minor contribution from CYP2E1. Pharmacodynamic systems influenced by PGx are: GABA A/B receptors, glutamate (NMDA and $\alpha$-amino-3-hydroxyl-5-methyl-isoxazolepropionate), serotonin, voltage-activated calcium channels, dopamine/norepinepherine/ acetylcholine and opioid systems. For example, naltrexone, used for detoxification, binds to opioid receptor $\mu 1$, and the variants of the candidate gene of this receptor may affect addiction treatment $[32,33]$.

\section{Antidepressants \& antipsychotics}

Personalized justice might address the effect of antidepressant and/or antipsychotics on behavioral changes. A recent review examined the relationship of violent behavior to the antidepressants: paroxetine, sertraline and fluoxetine. Different verdicts in a series of medicolegal cases reflected the different judicial processes, without considering drug-induced violence [34]. Incidentally, co-author Lucire studied patients medicated with antidepressants and antipsychotics metabolized by polymorphic CYPs, and assessed the development of akathisic, suicidal and/or homicidal ideations, and their relationship to $C Y P$ gene variations [Lucire Y, Pers. Сомm.]. The validity of these preliminary observations are pending publication in peer-reviewed journals and validation by other investigators.

Box 1. Advantages and disadvantages of using pharmacogenomics as an adjunct biomarker in personalized justice.

\section{Advantages:}

- DNA is stable in postmortem settings

- It provides a personalized approach for assessing drug response

- It can assist in the interpretation of drug concentrations in postmortem toxicology and drug death certification

- It can assess patient compliance

- The turnaround time is suitable for medicolegal and/or forensic applications

"The cost of pharmacogenomics is 'low' in comparison with the legal settlement

- It might differentiate between chronic versus acute toxicity

\section{Disadvantages:}

- Data are available in clinical cases but are limited in postmortem cases

- Legal interpretation is challenging owing to its complexity

- Drug inhibitors, inducers of enzymes and environmental factors complicate interpretation

- It does not account for post-translational modifications

- Multiple enzyme systems are involved in metabolism

\section{Warfarin}

Oral warfarin anticoagulation is widely used to prevent thromboembolic events. Dosing selection is due to a narrow therapeutic range with a large interindividual variation (20-fold) affected by genetic and nongenetic factors $[35,36]$. Approximately $10-17 \%$ of patients experience bleeding [35]. Genotyping of CYP2C9, CYP4F2, $V K O R C 1$ and relevant clinical factors account for up to approximately $56 \%$ of dosing variability [37,38]. In 2007, the FDA relabeled warfarin to suggest genotyping, followed by the 22 January 2010 relabeling [4]:

\section{"The patient's CYP2C9 and VKORC1 geno- type information, when available, can assist in selection of the starting dose."}

Previously, in May 2009, the Centers for Medicare and Medicaid Services recommended against reimbursement [106]. Potential legal culpability was addressed in the introduction.

\section{Pain management}

In addressing pain management with safety, Dr Woodcock of the FDA discussed the balance of providing patients with efficacious analgesics and the associated risks [39]. For example, in ultrarapid metabolizers, greater CYP2D6 activity can lead to poisoning after opioid administration. A 2007 case report detailed a breast-feeding infant who suffered respiratory depression and died as a result of toxic amounts of morphine being present in the milk [40]. The mother, later identified with multiple copies of CYP2D 6 genes corresponding to an ultrarapid metabolizer, 'overconverted' codeine to a 'high' amount of morphine. This was excreted into breast milk, resulting in the baby's high morphine concentrations, which was identified in postmortem analysis. Consequently, guidelines were developed for breast-feeding mothers medicated with codeine.

\section{Conclusion}

In recognizing the complementary, check and balance relationship of PM and PJ, translational PGx may serve the promising role of an adjunct biomarker for interpreting drug-related toxicity and sensitivity. Currently, robust, scientific and clinical studies substantiating the relationship between PGx and behavioral and/or performance changes are lacking [34]. These desired PJ studies are challenging to perform because of ethical and legal considerations and a lack of funding. Consequently, interpretations may be extrapolated from case reports, or clinical 
behavioral and performance studies; for example, studies related to 'driving under the influence of drug'. Other advances include automated platforms and the potential use of oral fluid for toxicology and PGx. Oral fluid, currently being evaluated for forensic drug testing [41-44] and therapeutic drug monitoring, is easily collected for PM and PJ pending outcome studies to demonstrate efficacy comparable to blood samples. In considering PGx for PJ, advantages and disadvantages are listed in Box 1 .

In ushering PJ practice in with PGx, a working group should consist of colleagues from inter-related disciplines in order to probe and keep abreast of recent developments, to grade evidence of case reports and outcome studies, and to develop inclusion and exclusion criteria. With sound scientific and legal principles and correct interpretation, a firm and lasting foundation could support the emerging concept of PJ becoming a reality to enhance patient safety and maintain social justice.

\section{Disclosure}

This article reflects the consensus of the co-authors and not the official position of opinion of their respective employers.

\section{Financial \& competing interests disclosure}

The authors have no relevant affiliations or financial involvement with any organization or entity with a financial interest in or financial conflict with the subject matter or materials discussed in the manuscript. This includes employment, consultancies, honoraria, stock ownership or options, expert testimony, grants or patents received or pending, or royalties.

No writing assistance was utilized in the production of this manuscript.

\section{Bibliography}

Papers of special note have been highlighted as: - of interest

" of considerable interest

1 Miller ED: A bold leap into the future personalized medicine is key to the new genes to society curriculum. In: Hopkins Medicine. Pasquale SE (Ed.). Johns Hopkins Medicine, Baltimore, MD, USA, 48 (2009).

2 Wu AHB, Babic N, Yeo KTJ: Implementation of pharmacogenomics into the clinical practice of therapeutics: issues for the clinician and the laboratorian. Per. Med. 6, 315-327 (2009).

3 Wadelius M, Pirmohamed M: Pharmacogenetics of warfarin: current status and future challenges. Pharmacogenomics J. 8(7), 99-111 (2007).

4 Ray T: FDA updates warfarin labeling with PGx-guided dosing ranges. Pharmacogenomics Reporter 3 February 2010.

5 Wong SH: Pharmacogenomics and personalized medicine for drug addiction and toxicology: towards personalized justice? Presented at: 11th Asian Pacific Congress of Clinical Biochemistry. Beijing, China, 14-19 October 2007.

- Introduces for the first time the concept of personalized justice at an international scientific congress.

6 Wong SHY, Happy C: Personalized justice, translational pharmacogenomics and personalized medicine - relevant to the forensic sciences? Tox. Talk 33, 22-23 (2009).

7 Wong SH, JM Jentzen, RZ Shi; the Forensic Pathology/Toxicology Methadone Pharmacogenomics Study Group
(FPTMPGxSG): Personalized medicine enabling personalized justice: methadone pharmacogenomics as an adjunct - for molecular autopsy, and for addiction and driving under the influence of drugs (DUID). Clin. Chem. Lab. Med. 46, A118 (2008).

8 Wong SHY: Pharmacogenomics as molecular autopsy - an adjunct to forensic pathology/ toxicology: from Gregor Mendel to personalized medicine and personalized justice. In: Clarke's Analysis of Drugs and Poisons (4th Edition). Moffat AC, Osselton DM, Widdop B (Eds). Royal Pharmaceutical Society Publishing, London, UK (2010) (In Press).

- First publication of the concept of personalized justice.

9 Jeffreys AJ, Wilson V, Thein SL: Individual-specific 'fingerprints' of human DNA. Nature 316(6023), 76-79 (1985).

=- Beginning of the practice of DNA fingerprinting.

10 Sallee FR, DeVane CL, Ferrell RE: Fluoxetine-related death in a child with cytochrome P-450 2D6 genetic deficiency. J. Child. Adolesc. Psychopharmacol. 10, 327-334 (2000).

- Published index case that included pharmacogenetics for interpreting fluoxetine toxicity.

11 Cote JF, Kirzin S, Kramar A et al:: UGTIAI polymorphism can predict hematologic toxicigy inpatients treated with irinotecan. Clin. Cancer Res. 13, 3269-3275 (2007).

12 Mallal S, Phillips E, Carosi G et al:: $H L A-B^{*} 5701$ screening for hypersensitivity to abacavir. N. Engl. J. Med. 358, 568-579 (2008).
13 Chung WH, Hung SI, Hong HS et al.: Medical genetics: a marker for Stevens-Johnson syndrome. Nature 428, 486 (2004).

"- Reports the association of Stevens-Johnson syndrome with the $H L A-^{*} B 1502$ allele.

14 Committee on Identifying the Needs of the Forensic Science Community - National Research Council of the National Academies: Strengthening Forensic Science in the United States: A Path Forward. National Academy of Sciences. The National Academies Press, Washington, DC, USA, 1-352 (2009).

" National Academy of Science identified deficiencies in several areas of forensic sciences and offered recommendations for the future.

15 American Academy of Forensic Sciences: The American Academy of Forensic Sciences approved position statement in response to National Academy of Sciences' "Forensic Needs" Report. American Academy Of Forensic Sciences, CO, USA (2009).

16 Bohan TL: President's message. Academy News 39(1), 34-35 (2009).

17 Gianelli P: Understanding Evidence (3rd Edition). 323 (2003).

18 Federal Judicial Center: Reference Manual on Scientific Evidence (2nd Edition). Washington, DC, USA, 487 (2000).

19 Federal Rule of Evidence, 702, Testimony by Experts.

20 Kassirer JP, Cecil JS: Inconsistency in evidentiary standards for medical testimony: disorder in the courts. JAMA 288, 1382-1387 (2002). 
21 Penry v. Lynaugh, 429 US 302 (1989).

22 Roper v. Simmons, 543 US 551 (2005).

23 Atkins v. Virginia, 536 US 304 (2002).

24 Wong SHY, Wagner MA, Jentzen JM et al.: Pharmacogenomics as an adjunct of molecular autopsy for forensic pathology/toxicology: does genotyping CYP $2 D 6$ serve as an adjunct for certifying methadone toxicity? J. Forensic Sci. 48, 1406-1415 (2003).

25 Wong SHY, Gock SB, Shi RZ et al: Pharmacogenomics as an aspect of molecular autopsy for forensic pathology/toxicology. In: Pharmacogenomics and Proteomics: Enabling the Practice of Personalized Medicine. Wong SHY, Linder M, Valdes R Jr (Eds). AACC Press, Washington, DC, USA, 311-320 (2006).

26 Molina DK: Handbook of Forensic Toxicology for Medical Examiners. CRC Press, Boca Raton, FL, USA, 1-370 (2010) (Appendix C - PGXs, 343-347).

27 Karch SB: Karch's Pathology of Drug Abuse (4th Edition). CRC Press, Boca Raton, FL, USA, 1-709 (2009).

28 Ernst C, Mechawar N, Turecki G: Suicide neurobiology. Prog. Neurobiol. 89, 315-333 (2009).

29 Golgin E: Epigenetic suicide note. The Scientist, 18-19 August (2009).

30 Kim S, Misra A: SNP genotyping technologies and biomedical applications. Annu. Rev. Biomed. Eng. 9, 289-320 (2007).

31 Neuman MG, Malkiewicz IM, Shear NH: A novel lymphocyte toxicity assay to assess drug hypersensitivity syndromes. Clin. Biochem. 33, 517-524 (2000).

32 King AC, Volpicelli JR, Frazer A, O'Brien CP: Effect of naltrexone on subjective alcohol response in subjects at high and low risk for future alcohol dependence. Psychopharmacology 129, 15-22 (1997).

33 Wang JB, Imai Y, Eppler CM, Gregor P, Spivak CE, Uhl GR: $\mu$-opiate receptor: cDNA cloning and expression. Proc. Natl Acad. Sci. USA 90(21), 10230-10234 (1993).

34 Healy D, Herxheimer A, Menkes DB: Antidepressants and violence: problems at the interface of medicine and law. PloS 3 , 1478-1487 (2006).

- Comprehensive review of candidate antidepressant cases that showed potential legal implications.

35 Stehle S, Kirchheiner U, Lazar A, Fuhr U: PGXs of oral anticoagulants. Clin. Pharmacokin. 47, 565-594 (2008).

36 Kangelaris KN, Bent $S$, Nussbaum RL, Garcia DA, Tice JA: Genetic testing before anticoagulation?
A systematic review of PGX dosing of warfarin. J. Gen. Intern. Med. 24, 656-664 (2009).

37 Caldwell MD, Awad T, Johnson JA et al.: CYP4F2 genetic variant alters required warfarin dose. Blood 111, 4106-4112 (2008).

38 Gage BF, Eby C, Johnson JA et al.: Use of PGX and clinical factors to predict the therapeutic dose of warfarin. Clin. Pharmacol. Ther. 84, 326-331 (2008).

39 Woodcock J: A difficult balance - pain management, drug safety and the FDA. N. Engl. J. Med. 361, 2105-2107 (2009).

- US FDA perspective centered around pain management and drug safety.

40 Madadi P, Koren G, Cairns J et al.: Safety of codeine during breastfeeding: fatal morphine poisoning in the breastfed neonate of a mother prescribed codeine. Can. Fam. Phys. 53, 33-35 (2007).

41 Bosker WM, Huestis MA: Oral fluid testing for drugs of abuse. Clin. Chem. 55, 1910-1931 (2009).

42 Cone EJ, Huestis MA: Interpretation of oral fluid tests for drugs of abuse. Ann. NY Acad. Sci. 1098, 51-103 (2007).

43 Pil K, Verstraete AZ: Current developments in drug testing in oral fluids. Ther. Drug Monit. 30, 196-202 (2008).

44 Bush DM: The U.S. Mandatory Guidelines for Federal Workplace Drug Testing Programs: current status and future considerations. Forensic Sci. Int. 174, 111-119 (2008).

\section{Websites}

101 Coumadin $^{\circledR}$ Tablets (Warfarin Sodium Tablets, USP) Crystalline Coumadin ${ }^{\circledR}$ For Injection (Warfarin Sodium for Injection, USP) www.accessdata.fda.gov/drugsatfda_docs/ label/2010/009218s108lbl.pdf

102 Coumadin Overdose, Warfarin Overdose, Law Examples www.spanglaw.com/medical-malpractice/ medication-errors/coumadin

103 SSJ Law http://ssjlaw.mobi

104 Strengthening Forensic Science in the United States: A Path Forward www.nap.edu/catalog/12589.html

105 The American Academy of Forensic Sciences Approves Position Statement in Response to the National Academy of Sciences' "Forensic Needs" Report www.aafs.org/pdf/AAFS_Position_ Statement_for_Press_Distribution_ 090409.pdf
106 Centers for Medicare and Medicaid Services www.cms.hhs.gov/mcd/ viewdraftdecisionmemo. asp? from $2=$ viewdraftdecision memo. asp \&id $=224 \&$

\section{Affiliations}

\section{- Steven HY Wong, PhD}

Professsor of Pathology, Psychiatry and Behavioral Medicine, and Population Health-Epidemiology and Director of Toxicology and TDM, Medical College of Wisconsin, Milwaukee,

WI 53226-0509, USA

Tel.: +1 4148056971

Fax: +1 4148056980

shwong@mcw.edu

and

Scientific Director, Toxicology Department and Pharmacogenomics, Milwaukee County Medical Examiner's Office, WI, USA

- Christopher Happy, MD

Medical Examiner of Milwaukee County and Assistant Professor of Pathology, Medical College of Wisconsin, Milwaukee,

WI 53233, USA

- Dan Blinka, JD, PhD

Professor, Marquette Law School,

Milwaukee, WI 53233, USA

- Susan Gock, MSc

Technical Director, Toxicology Department, Milwaukee County Medical Examiner's

Office, WI, USA

and

Instructor of Pathology, Medical College of

Wisconsin, Milwaukee, WI 53233, USA

- Jeffrey M Jentzen, MD, PhD

Professor of Pathology and Director of Autopsy Services, University of Michigan, Ann Arbor, MI, USA

- Honorable Judge M Joseph Donald, JD Milwaukee County Circuit Court Branch 2, Milwaukee County Safety Building, Room 423, Milwaukee, WI 53233 , USA

\section{- Howard Coleman}

Genelex Corporation, 3000 First Avenue, Suite One, Seattle, WA 98121, USA

- Saeed A Jortani, PhD

Associate Professor, Department of Pathology and Laboratory Medicine, University of Louisville, 511 S. Floyd Street (Room 217A), Louisville, KY 40202, USA

- Yolande Lucire, PhD, MBBS

Forensic and Medico-Legal Psychiatry, Level 5, 203-233 New South Head Road, NSW 2027, Australia

- Cynthia Morris-Kukoski, PharmD Forensic Examiner Toxicology, FBI Laboratory, Quantico, VA, USA and

Clinical Pharmacologist/Toxicologist, United States Navy Reserves, USA 
- Manuela Neuman, PhD

Associate Professor of Pharmacology, Biophysics and International Health, Department of Pharmacology \& Institute of Drug Research, USA and Director of In vitro Drug Safety \& BioTechnology, MaRS Discovery District, 101 College Street, Suite 300, Laboratory 351, Toronto, ON, M5G 1L7, Canada

- Paul J Orsulak, PhD, MBA

Consultant, Clincal and Forensic Toxicology, Minneapolis, MN, USA

- Tara Sander, PhD

Associate Professor of Pathology, Medical College of Wisconsin, USA and

Director, Molecular Diagnostics of Children's Hospital of Wisconsin, Milwaukee, WI 53226, USA
- Michael A Wagner, PhD

Associate Professor, Department of Pharmacology and Toxicology and Department of Pathology, Indiana University School of Medicine, USA and Director, Indiana State Department of Toxicology, 550 W. 16th Street, Indianapolis, IN 46202, USA

- Jennifer R Wynn, PhD

Assistant Professor of Criminal Justice, Coordinator, Joint Criminal Justice Program, Department of Law, Police Science and Criminal Justice Administration, LaGuardia Community College and John Jay College of Criminal Justice, 899 10th Avenue, New York, NY 10019, USA
- Alan HB Wu, PhD

Professor of Pathology and Laboratory Medicine, University of California San Francisco, San Francisco General Hospital, 1001 Potrero Avenue, San Francisco, CA 94110, USA

- Kiang-Teck J Yeo, PhD Professor of Pathology, Director, Clinical Chemistry, UC Med Laboratory, and Pharmacogenomics Program, University of Chicago, Chicago, IL 60637, USA 